Preface

\title{
ICMCTF 2014 - Preface
}

\author{
S. Aouadi, E. Broitman, M. Stüber, S. Veprek, F. Robert
}

The 41st International Conference on Metallurgical Coatings and Thin Films (ICMCTF), sponsored by the Advanced Surface Engineering Division (ASED) of the American Vacuum Society (AVS), was held from April 28 to May 2, 2014 in San Diego, California, USA.

The week's technical program consisted of 37 technical sessions, which were organized into 13 symposia. The conference opened with a Plenary Lecture by Prof. Sybrand van der Zwaag, Materials Science and Engineering at the faculty of Aerospace Engineering at the TU Delft, The Netherlands, on "Self-healing Materials: an Alternative Approach to Create More Durable/Reliable Materials and Products". The Exhibition Keynote Lecture was presented by Prof. Timothy P. Weihs, Department of Materials Science and Engineering at the Johns Hopkins University, Baltimore, MD, USA, on "Driving Commercial Applications and Exploring Scientific Questions with Reactive Multilayer Foils".

During the conference week, a well subscribed poster session was attended by a large and appreciative attendee audience. An expansive large two-day interactive industrial exhibition, with more than 50 booths,was held inwhich companies displayed theirmost recent developments in vacuumscience and plasma-based deposition technologies.

In addition to the technical symposia sessions, there were three focused topical sessions, and six specialized short courses offered.

Professor Jindrich Musil from the faculty of Applied Sciences at the University of Bohemia, Plzeň, Czech Republic, was the recipient of the 2014 ASED R.F. Bunshah Annual Award; he presented the Honorary Lecture, "Advanced Hard Nanocomposite Coatings with Unique Properties". The award recognizes and honors Prof. Musil's seminal contributions to the development of advanced nanocomposite coatings with enhanced hardness, oxidation resistance, toughness, and crackresistance.

The ASED Annual ICMCTF Graduate Student Awards were presented to Shiyu Liu (Gold Medal), University of Cambridge, UK; Samantha K. Lawrence (Silver Medal), 
Purdue University, West Lafayette, IN, USA; and Trevor Hardcastle (Bronze Medal), University of Leeds, UK.

The electronic submission and handling of manuscripts via the Elsevier Editorial System (EES), including the selection of reviewers and evaluation of manuscripts,were identical to the procedures applied to manuscripts submitted as regular contributions for publication in international scientific journals. Following the tradition practiced since 1987, the accepted manuscripts are published in the archival journals Surface and Coatings Technology and Thin Solid Films. ICMCTF 2014 proceedings are open-access to the participants for one year via the Elsevier journals' web sites.

The organization of this conference and the preparation of proceedings volumes would have been impossible without the tremendous effort and dedication of many individuals, including the General Chair, Yip-Wah Chung, Northwestern University, USA, and the Program Chair, Claus Rebholz, the University of Cyprus, the team of symposia and session chairs that made possible the realization of an exciting technical program. We especially thank all the authors and presenters for their contributions; we also thank the hundreds of reviewers for their timely submission of high quality reports. To our sponsors, we acknowledge, appreciate, and thank these companies for their most generous and continuing support.

The 42nd International Conference on Metallurgical Coatings and Thin Films (ICMCTF 2015) will be held in San Diego, California, April 20-24, 2015, with Claus Rebholz, University of Cyprus, as the General Chair and Suneel Kodambaka, the University of California at Los Angeles, as the Program Chair.

Samir Aouadi

Proceedings Editor

Esteban Broitman

Proceedings Editor

Michael Stüber

Proceedings Editor, Publications Chair

Stan Veprek

Proceedings Editor

Robert Franz

Proceedings Editor 